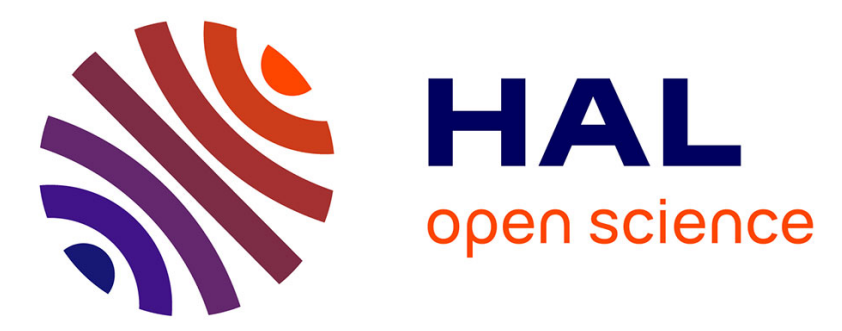

\title{
Structural phase transition in p-quaterphenyl : a Raman study of the influence of temperature and pressure
}

\author{
A. Girard, Y. Délugeard, L. Pichon, B. Toudic
}

\section{To cite this version:}

A. Girard, Y. Délugeard, L. Pichon, B. Toudic. Structural phase transition in p-quaterphenyl: a Raman study of the influence of temperature and pressure. Journal de Physique I, 1992, 2 (9), pp.1833-1846. 10.1051/jp1:1992249 . jpa-00246664

\section{HAL Id: jpa-00246664 https://hal.science/jpa-00246664}

Submitted on 1 Jan 1992

HAL is a multi-disciplinary open access archive for the deposit and dissemination of scientific research documents, whether they are published or not. The documents may come from teaching and research institutions in France or abroad, or from public or private research centers.
L'archive ouverte pluridisciplinaire HAL, est destinée au dépôt et à la diffusion de documents scientifiques de niveau recherche, publiés ou non, émanant des établissements d'enseignement et de recherche français ou étrangers, des laboratoires publics ou privés. 


\title{
Structural phase transition in p-quaterphenyl : a Raman study of the influence of temperature and pressure
}

\author{
A. Girard, Y. Délugeard, L. Pichon and B. Toudic \\ Groupe Matière Condensée et Matériaux $\left(^{*}\right)$, Université de Rennes I, Campus de Beaulieu, \\ 35042 Rennes Cedex, France
}

(Received 27 December 1991, accepted in final form 30 March 1992)

\begin{abstract}
Résumé. - Une étude par diffusion Raman du p-quaterphényle est présentée en fonction de la température et de la pression. A pression atmosphérique, un élargissement de bande au voisinage de la transition donne un support direct du mécanisme ordre-désordre. Le diagramme de phase a été déterminé. Le mécanisme de la transition est analysé jusqu'à 4 kbar et montre une évolution vers un régime displacif, la transition restant continue.

Abstract. - A Raman scattering study of p-quaterphenyl is reported as function of temperature and pressure. At atmospheric pressure, a line broadening in the vicinity of the transition gives a direct support of the order-disorder mechanism. The phase diagram has been determined. The mechanism of the transition is analysed up to 4 kbar and shows an evolution towards a displacive regime, the transition remaining continuous.
\end{abstract}

\section{Introduction.}

In molecular crystals, the structural instabilities result often from a delicate balance between relatively weak forces. For this reason the application of even rather weak pressures (up to few kbar) may already drastically change the local potential involved. The p-polyphenyl series represents such an example. These molecules consist of phenyl rings connected by single C-C bonds in para position. In the gaseous state the molecules exhibit a torsional angle between phenyl rings due to antagonistic intramolecular forces : the delocalization of $\pi$ electrons and the repulsion of ortho hydrogen atoms. These forces induce a double well intramolecular potential which, in the simplest case, may be described in the following way:

$$
V_{\text {intra }}=A \varphi^{2}+B \varphi^{4} \text { with } A<0 .
$$

The relative values of $A$ and $B$ define the barrier height and the positions of the minima of this intramolecular potential. In the crystalline state the intermolecular forces favor the planar configuration and so may be described by a single well shape potential :

$$
V_{\text {inter }}=L \varphi^{2} \quad \text { with } L>0 \text {. }
$$

(*) URA au CNRS 804. 
This $L$ coefficient reduces the value of the negative term in the effective potential. To change the barrier height one may modify any of the two above parameters :

- $A$ is an intramolecular parameter connected with the number of pairs of repulsive hydrogen atoms. The absolute value of $A$ should increase with the number of phenyl rings, i.e. from biphenyl to p-quaterphenyl. Let us mention that isotopic substitution of hydrogen atoms by deuterium atoms was also found to modify $A$ reducing it $[1,2]$.

- The $L$ parameter magnitude is connected to the compactness of the structure. So $L$ should increase with pressure.

Because of these different possibilities, the series of p-polyphenyls is well suited to study different cases of structural phase transitions. Their common high temperature structure is monoclinic and the space group is $\mathrm{P} 2_{1} / \mathrm{a}$. Whereas it is well known that, at atmospheric pressure, biphenyl presents a displacive phase transition with incommensurate phases [3], $\mathrm{p}$ terphenyl shows a pure and almost continuous order-disorder phase transition towards a triclinic structure [4-6]. Under pressure, the transition temperatures of these compounds decrease yielding very interesting phenomena. In biphenyl around $2 \mathrm{kbar}$, the transition temperature drops to $0 \mathrm{~K}$ and we are in the so-called displacive limit $[3,7]$. The persistence of the incommensurate phase there has furthermore allowed very precise neutron [8,9] and Raman [10] analysis of the characteristic excitations with the smallest possible damping. The study of the pressure influence on the structural instabilities in p-terphenyl has been very fruitful. Indeed both Raman [1, 11] and neutron [12, 13] scattering studies show a changeover from the order-disorder to the displacive regime with a whole phonon branch softening. So, this compound gives us an opportunity to study the dynamics not only in the pure orderdisorder and displacive regimes but also in any intermediate state. A problem however appears as the phase transition of p-terphenyl, already very weakly first order at atmospheric pressure, becomes clearly first order under pressure. All these results have allowed the above description of the antagonistic forces in p-polyphenyls. This has even provided a rare understanding of the origin of the frustrated forces yielding incommensurate phases in nonmagnetic crystals [14].

However a few questions remain concerning the forces involved. For instance the soft mode in biphenyl at all temperatures and pressures condenses around the $Z(0,1 / 2,0)$ point, using the high temperature monoclinic space group $\mathrm{P} 12_{1} / \mathrm{a} 1$, whereas in p-terphenyl there are, under pressure, two types of ordered phase, one resulting from a condensation at the $\mathrm{C}(1 / 2$, $1 / 2,0)$ point and the other at the $\mathrm{E}(1 / 2,1 / 2,1 / 2)$ point (Zak's notation [15] where $x, y, z$ refer to $\mathbf{c}^{*}, \mathbf{a}^{*}, \mathbf{b}^{*}$ respectively $\left.[16]\right)[5,12-13]$. More generally another interesting point concerns the dynamics in more complex systems as obtained by increasing the number of phenyl rings in polyphenyls.

In order to improve our understanding of such systems we have performed a Raman scattering study of p-quaterphenyl. In part 2 of this paper we review the previous studies on this compound. In part 3 the experimental conditions are described. We reexamine the signature of the transition in part 4 whereas part 5 deals with the study under pressure. Discussion and conclusion are in part 6.

\section{Previous results on p-quaterphenyl.}

This compound has been much less studied than the others of the series. X-ray diffraction [17] shows that, in the high temperature phase, p-quaterphenyl is isostructural to biphenyl and pterphenyl. The space group is $\mathrm{P} 2 / \mathrm{a}$ with $Z=2$. This study has also shown that the mean conformation of the molecules is planar and so they are centrosymmetric. As in p-terphenyl, this conformation could be attributed to a dynamical disorder between two non-planar 
conformations. This was indeed confirmed by a low temperature X-ray analysis [18] which showed that, in this ordered phase, two non-planar conformations are related to the existence of a torsional angle between planes of phenyl rings. These conformations may be described in terms of double well potential. One well of the local potential is associated with the molecular conformation $(+,-,+,-)$ and the other with the conformation $(-,+,-,+)$, where the + and - symbols indicate the positive or negative direction of rotation of each phenyl ring with respect to the mean molecular plane. The low temperature space group is $\mathrm{P} \overline{1}$ with $Z=4$ [18]. However, unlike p-terphenyl molecules, the p-quaterphenyl molecules do not conserve their center of symmetry at low temperature but the center of symmetry located between two molecules is preserved. As in p-terphenyl the superstructure reflexions appear at the zone boundary point $\mathrm{C}(1 / 2,1 / 2,0)$ at atmospheric pressure, with a doubling of the high temperature unit cell in the $(\mathbf{a}, \mathbf{b})$ plane. The Brillouin observation of an anomaly of the longitudinal sound velocity recorded along the a axis suggested that the transition temperature $T_{\mathrm{c}}$ was about $240 \mathrm{~K}$ at atmospheric pressure, but no conclusion could be made for the type of transition [19]. Later, N.M.R. experiments [20] revealed a critical slowing down of the fluctuations similar to that existing in p-terphenyl : the spin-lattice relaxation rate presents a drastic increase in the vicinity of the transition temperature. Far from $T_{c}$ an Arrhenius behaviour of the relaxation rate is observed. This has been attributed to the random single reorientational jump motion of the molecules of p-terphenyl in their local double well potential. The activation energy for this motion was found to be equal to $E_{\mathrm{a}}=$ $1.85 \mathrm{kcal} . \mathrm{mole}^{-1}$ confirming the order-disorder mechanism. This value is higher than in $\mathrm{p}$ terphenyl $E_{\mathrm{a}}=1.05 \mathrm{kcal} . \mathrm{mole}^{-1}$ As mentioned in the introduction this increase can be attributed to the larger number of phenyl rings which induces a larger contribution of the intramolecular repulsive forces.

Some years ago, a Raman analysis [21] also concluded to an order-disorder mechanism, although it did not provide any direct support such as the broadening of phonon lines through the transition. Still the results appeared to argue against a displacive mechanism (lack of soft mode). As a signature of the transition, the authors retained an apparent band splitting which seems to disappear at $250 \mathrm{~K} \pm 20 \mathrm{~K}$ when extrapoled.

The purpose of our Raman study is, first, to verify if this band splitting can be due to the phase transition, second, to provide a direct support of the transition mechanism, and third, to examine the effects of pressure to see if the model of competition between intramolecular and intermolecular forces can be applied to p-quaterphenyl.

\section{Experimental procedure.}

The p-quaterphenyl was of commercial origin (Aldrich). Single crystals were grown by the Bridgman technique after several melting refinements. The samples were cut along $a, b$ and $c^{*}$ directions to obtain a right angled parallelepipedic shape. Spectra were recorded, in a $90^{\circ}$ scattering geometry, with a LRDH 800 Coderg Raman spectrometer and using a CR2 argon ion laser $(5145 \AA)$. For atmospheric pressure experiments, the samples were cooled in a controlled stream of cold nitrogen gas inside a Meric cryostat. For high pressure experiments, the samples were set in a pressure cell inserted itself in a SMC cryostat of the same type that the Meric one. The pressure cell was designed and built at the Department des Hautes Pressions of the University of Paris VI. The pressure transmitting medium was helium gas. The pressure and temperature stabilities were, respectively, better than 10 bar and $0.1 \mathrm{~K}$. This ensemble permitted us to go up to $4 \mathrm{kbar}$ and down to liquid helium temperature [22].

As described in a previous paper [1], the experimental lines have been deconvoluted from the resolution function and then refined by a least squares method. To evaluate the accuracy of 
the fits, a reliability factor $R$, comparable to the crystallographic one, is calculated :

$$
R=\frac{\sum_{i=1}^{n}\left|E_{i}^{0}-E_{l}^{\mathrm{c}}\right|}{\sum_{i=1}^{n} E_{l}^{0}}
$$

with $E_{\imath}^{0}$ experimental points and $E_{\imath}^{\mathfrak{c}}$ calculated points.

This $R$ factor is very useful in all the cases where the number of lines is difficult to estimate.

\section{Raman signature of the transition.}

Our Raman study on the signature of the transition has been performed in the low frequency range $\left(7 \mathrm{~cm}^{-1}-150 \mathrm{~cm}^{-1}\right)$. For p-quaterphenyl what are the modes which can be expected in this frequency range? Previous papers on biphenyl and p-terphenyl crystals [23-25] furnish such information on the Raman active modes :

- the librational internal modes around the long molecular axis. These torsions have a preponderant role in p-polyphenyls structural transitions ;

- some modes which correspond to out-of-plane displacements of benzene rings and some others which correspond to angular deformations between the central bond and the rings can also lie in this spectral range;

- the lattice modes.

In the high temperature phase, as discussed below, the disorder may produce lines broadenings. So the experimental Raman spectrum is principally constituted of very broad bands and no comparison can be made with the group theory prediction (six external modes and two librational internal modes active in Raman scattering). In the low temperature phase, for two reasons, some new modes can appear in the Raman spectra :

- the transition being a zone boundary one, the modes located at the $C(1 / 2,1 / 2,0)$ point can become active ;

- the used diffusion geometry $\mathbf{a}\left(\mathbf{c}^{*} \mathbf{a}\right) \mathbf{c}^{*}$ corresponds to $\mathrm{Ag}$ modes in the high temperature phase but, for this diffusion geometry, the $\mathrm{Bg}$ modes of the high temperature phase can also become active in the low temperature phase.

The group theory prediction gives, for the low temperature phase, twelve external modes and six internal modes active in Raman scattering. The experimental spectrum at $T=39 \mathrm{~K}$ [21] shows twenty-four bands below $200 \mathrm{~cm}^{-1}$, i.e. six more than predicted by the theory. So, it appears that, as for p-terphenyl, other internal modes (out-of-plane displacements or angular deformations) lie in this spectral range. Moreover, by comparison with biphenyl and p-terphenyl, the weight of the p-quaterphenyl molecule is larger. Then the number of internal modes increases in this spectral range and the coupling between internal and external modes should be more important in p-quaterphenyl. Consequently, as in $\mathrm{p}$ terphenyl, the different experimental lines should correspond to very complex molecular motions in the asymmetric unit.

Previously, Bolton and Prasad [21] have associated the splitting of the $34 \mathrm{~cm}^{-1}$ band with the structural phase transition. Our Raman study of p-quaterphenyl shows that this apparent splitting occurs at room temperature under pressure (Fig. 1). If one were to assume that this splitting is a signature of the transition, one should admit a phase diagram with positive slope $\left(\mathrm{d} T_{\mathrm{c}} / \mathrm{d} P>0\right.$ ) contrary to those of biphenyl and $\mathrm{p}$-terphenyl. This would mean that the transition mechanism of $p$-quaterphenyl should be different from the ones of biphenyl and $p$ - 


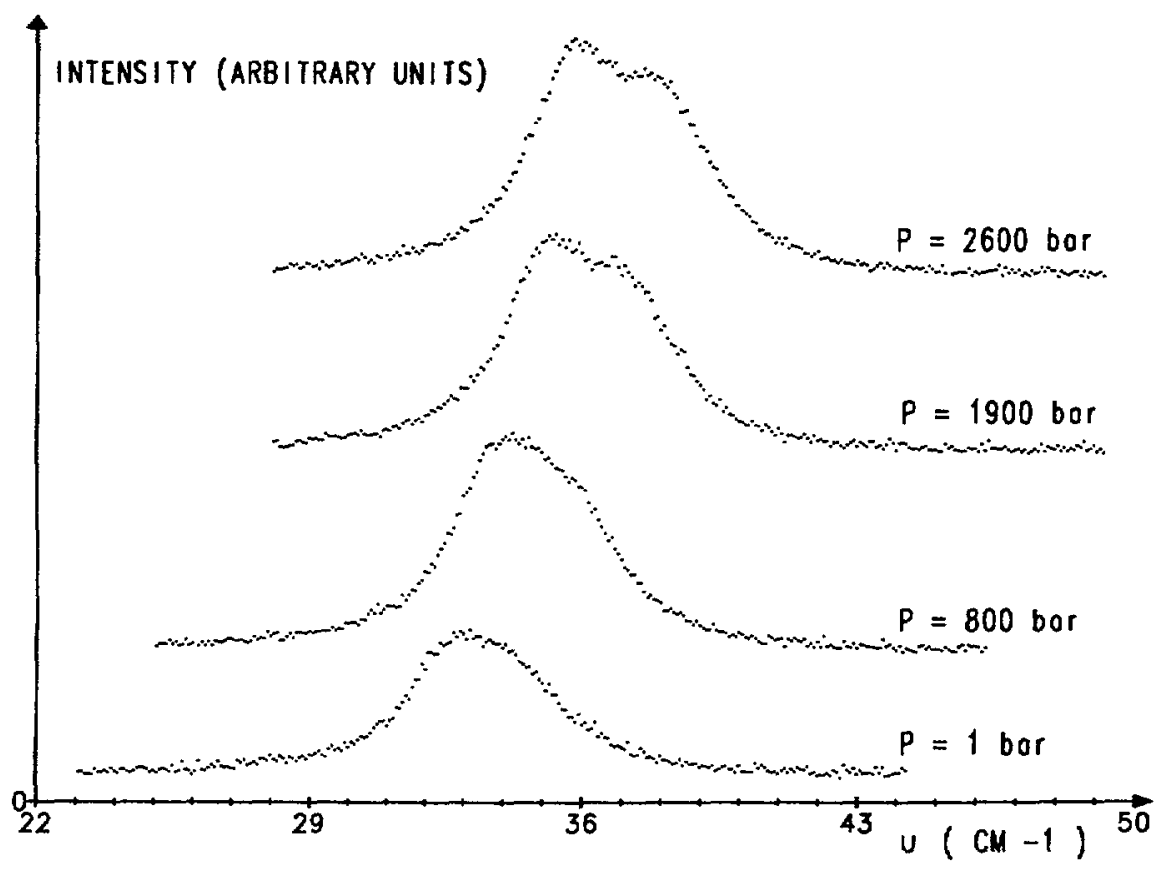

Fig. 1. - Evolution of the $22-50 \mathrm{~cm}^{-1}$ Raman spectral range of p-quaterphenyl at $T=293 \mathrm{~K}$ and at different pressures.

terphenyl. This situation was very curious for us and we have reinvestigated the Raman spectra at atmospheric pressure to try to elucidate this point.

Raman spectra of p-quaterphenyl have been recorded in the $\mathbf{a}\left(\mathbf{c}^{*} \mathbf{a}\right) \mathbf{c}^{*}$ geometry between $28 \mathrm{~cm}^{-1}$ and $49 \mathrm{~cm}^{-1}$ in the temperature range $80 \mathrm{~K}-300 \mathrm{~K}$ in order to determine accurately the spectral changes around the transition temperature. These spectra present the same general features as those observed by Bolton and Prasad [21]. We have also observed a splitting of the lowest frequency band into a triplet at low temperature. The chosen a $\left(\mathbf{c}^{*} \mathbf{a}\right) \mathbf{c}^{*}$ polarization allows to observe, at liquid nitrogen temperature, the first and third modes of the triplet with intensities of the same order of magnitude whereas the second is weaker. In this orientation the temperature dependence of the mode parameters is easier to observe despite modes overlapping when the temperature increases. In these experiments, it has been possible to deconvolute the experimental lines from the resolution function and to refine them using Lorentzian functions as it has been described for p-terphenyl [1]. Figure 2 shows the frequencies temperature dependences of the $30-40 \mathrm{~cm}^{-1}$ bands :

- Between $80 \mathrm{~K}$ and $140 \mathrm{~K}$ the Raman spectra have been fitted with three Lorentzian functions. The three frequencies vary linearly versus temperature. Note that the corresponding linewidths, which are of the same order of magnitude, are also linearly dependent of the temperature.

- Above $140 \mathrm{~K}$, the second mode seems to disappear. The refinements with two or three Lorentzian functions do not lead to significantly different reliability factors. So for higher temperatures the refinements have been carried out with only two Lorentzians. It will be noted that the vanishing of the second mode can be due to its overlapping with the first mode much more intense, implying that the refinement with three modes is not reliable. Above $140 \mathrm{~K}$, the frequencies and the linewidths of the two refined modes have a linear behaviour. 


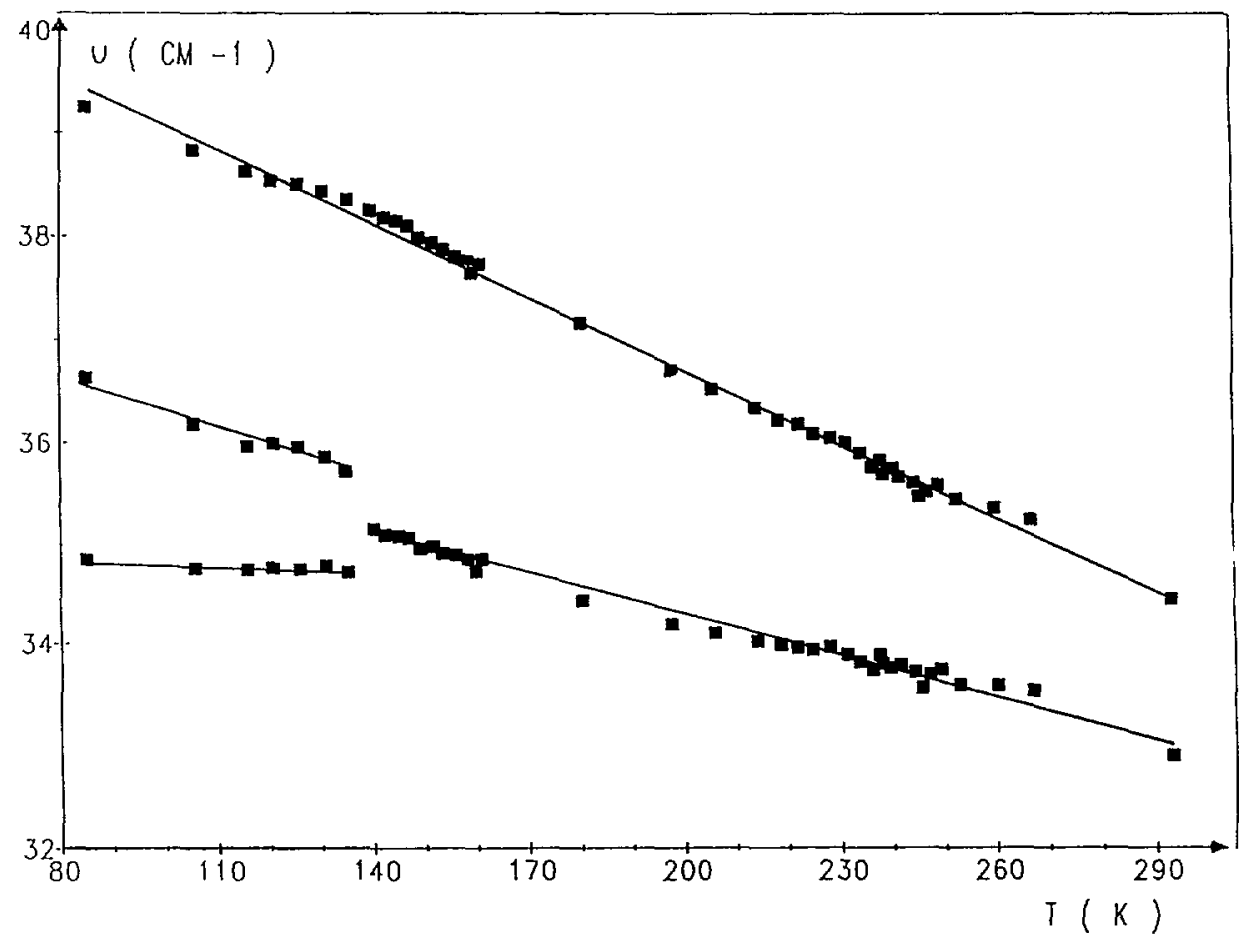

Fig. 2. - Frequencies dependence versus temperature of the triplet (see text) of p-quaterphenyl at atmospheric pressure. The straight lines are guides to the eye.

When the temperature increases, as observed by Bolton et al. [21], these two modes overlap and seem to give a single band. Nevertheless the refinements with one Lorentzian does not provide a good shape of the band and the reliability factors with two Lorentzians are much better than with one. Moreover figure 2 does not show any anomaly close to the transition temperature $240 \mathrm{~K}$. Then we can conclude for the persistence of the two modes in the temperature range $140 \mathrm{~K}-300 \mathrm{~K}$ and this even if only one band seems to be present in the spectrum above $180 \mathrm{~K}$. Therefore the splitting observed by Bolton et al. does not exist and, consequently, it cannot be associated with the structural phase transition. Concerning the linewidths of these two modes, their evolutions versus temperature also appear linear and no broadening is observed close to $T_{\mathrm{c}}$. However we note that, due to the strong overlapping of these two modes, the fits give linewidths with error bars which could hide a weak broadening.

We then had to search, in another spectral range, a direct evidence for the transition. As it is order-disorder, on increasing the temperature, one expects a broadening of the phonon lines in the vicinity of the transition. So we have studied the spectral evolution between 50 to $130 \mathrm{~cm}^{-1}$ from $130 \mathrm{~K}$ to $290 \mathrm{~K}$. In this spectral range, at $T=39 \mathrm{~K}$, Bolton et al. [21] observed fourteen bands whereas, at $T=140 \mathrm{~K}$, they observe, as we do, seven bands. Above $190 \mathrm{~K}$ only five bands are apparently present, the two less intense bands vanishing by overlapping. In any case, in the temperature range $136 \mathrm{~K}-200 \mathrm{~K}$, we have verified that the refinements performed respectively with seven or five bands give, for the central band linewidth, no significantly different values. Thus all the presented results have been determined with seven bands below $190 \mathrm{~K}$ and five bands from $190 \mathrm{~K}$ to $240 \mathrm{~K}$. Under these conditions, the corresponding refinements have shown that the intensities of two lines decrease progressively when approaching the transition temperature. Figure 3 , which shows this spectral range at three temperatures, exhibits this behaviour. In this scheme, all the individual Lorentzian 


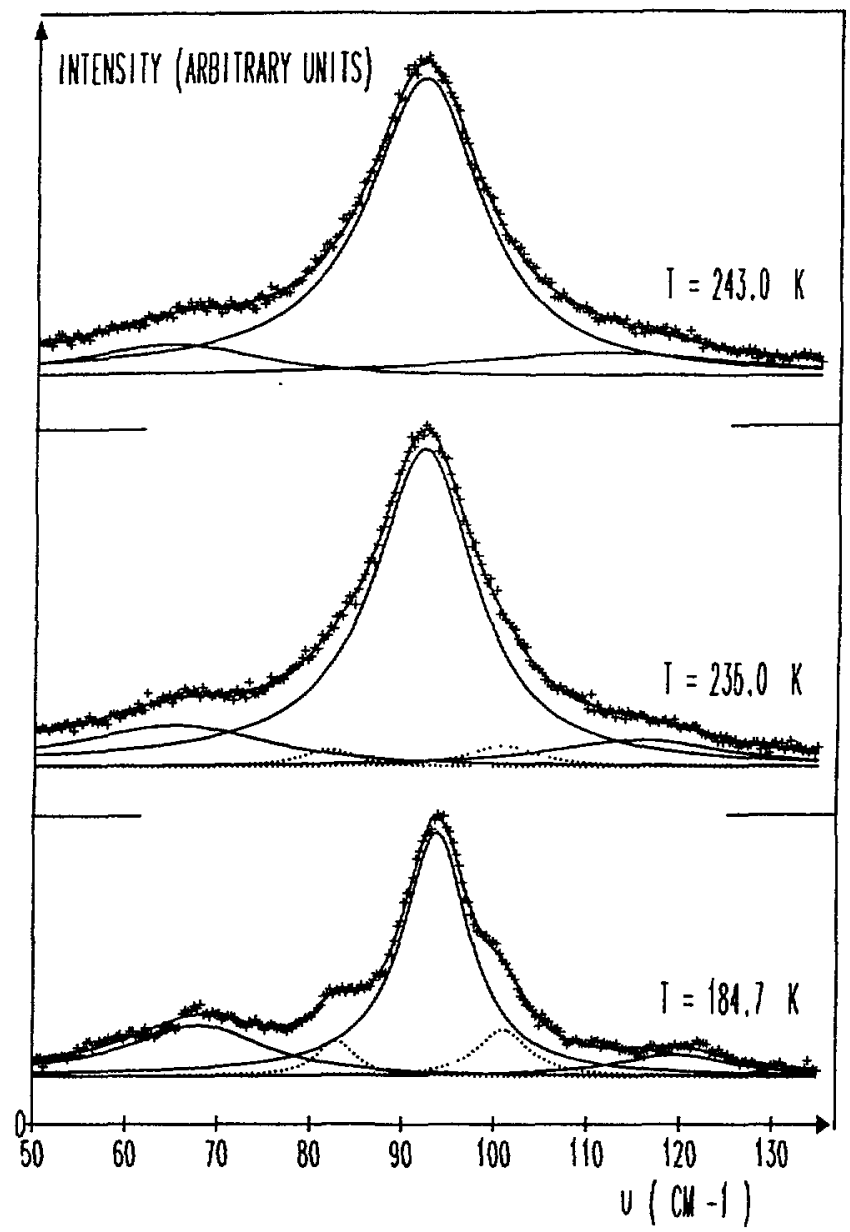

Fig. 3. - Spectral range $50-130 \mathrm{~cm}^{-1}$ of p-quaterphenyl at different temperatures and atmospheric pressure. In particular the figure shows the five individual Lorentzians at $T=184.7 \mathrm{~K}$ and $T=235.0 \mathrm{~K}$ and the three ones at $T=243.0 \mathrm{~K}$. Dotted lines represent the bands which vanish in the high temperature phase.

curves are plotted and, in particular, the bands whose intensity strongly decreases are represented as dotted lines at $184.7 \mathrm{~K}$ and $235.0 \mathrm{~K}$. Above $240 \mathrm{~K}$, refinements performed with three or five bands give similar values of $R$ reliability factors. (At $T=239.75 \mathrm{~K}$, $R=2.16 \%$ and $R=2.07 \%$ for respectively three and five bands.) We have then considered that the two corresponding bands are no longer more present and all the refinements have been achieved with only three Lorentzian functions. Figure 4 represents the linewidth dependence versus temperature of the third line. The inflexion point of the curve gives the transition temperature close to $240 \mathrm{~K}$. The interpretation of this evolution will be discussed below in relation with the other p-polyphenyls.

\section{Experimental results under pressure.}

In order to draw the $(P, T)$ phase diagram we have undertaken a study at $T=190 \mathrm{~K}$ under variable pressure in the spectral range $50-130 \mathrm{~cm}^{-1}$. The modes are normally shifted towards higher frequencies under pressure but, unfortunately, this shift goes with an increased 
overlapping. Therefore the refinements become less accurate and do not allow the transition pressure to be determined precisely.

By contrast, under pressure, in the low frequency spectral range $30-40 \mathrm{~cm}^{-1}$, the two bands separate and it becomes then possible to analyze their linewidth evolutions precisely. Thus we have recorded and fitted for p-quaterphenyl four sets of experiments at variable pressure and constant temperature $(175 \mathrm{~K}, 185 \mathrm{~K}, 198 \mathrm{~K}$ and $218 \mathrm{~K})$ and one set of experiments at constant pressure ( 4 kbar) and variable temperature. For the second band the linewidth behaviour is analogous to that shown in figure 4. As an example, figure 5 shows the linewidth pressure dependence at constant temperature (Fig. 5a) and the temperature dependence at constant pressure (Fig. $5 \mathrm{~b}$ ). The inflexion points of the curves give respectively the transition pressure $P_{\mathrm{c}}$ and the transition temperature $T_{\mathrm{c}}$ which allow us to determine the $(T, P)$ phase diagram. It is shown in figure 6 together with those of p-terphenyl and biphenyl. In these compounds, the transition temperatures decrease following a non-linear behaviour.

For the set of experiments at $175 \mathrm{~K}$ and variable pressure we have extended the spectral range covered out to $80 \mathrm{~cm}^{-1}$. Indeed, between this frequency and the two lowest frequency modes, three less intense bands appear (Fig. 7). For example, at atmospheric pressure, the frequencies of these three bands are equal to $47.4 \mathrm{~cm}^{-1}, 61.5 \mathrm{~cm}^{-1}$ and $71.0 \mathrm{~cm}^{-1}$ Note that the band around $47.4 \mathrm{~cm}^{-1}$, very weak at $P=1 \mathrm{bar}$, becomes more apparent for higher pressures. When pressure is applied, these bands remain well resolved up to $\left(P_{\mathrm{c}}-600\right)$ bar, then they broaden and overlap strongly to give a very broad band in the high temperature phase. The fits of these three lines have been carried out and an extensive study of the results has shown that the band around $61 \mathrm{~cm}^{-1}$ exhibits a very interesting behaviour. Figures $8 \mathrm{a}$ and $8 \mathrm{~b}$ show respectively its frequency and linewidth dependences versus pressure. This line

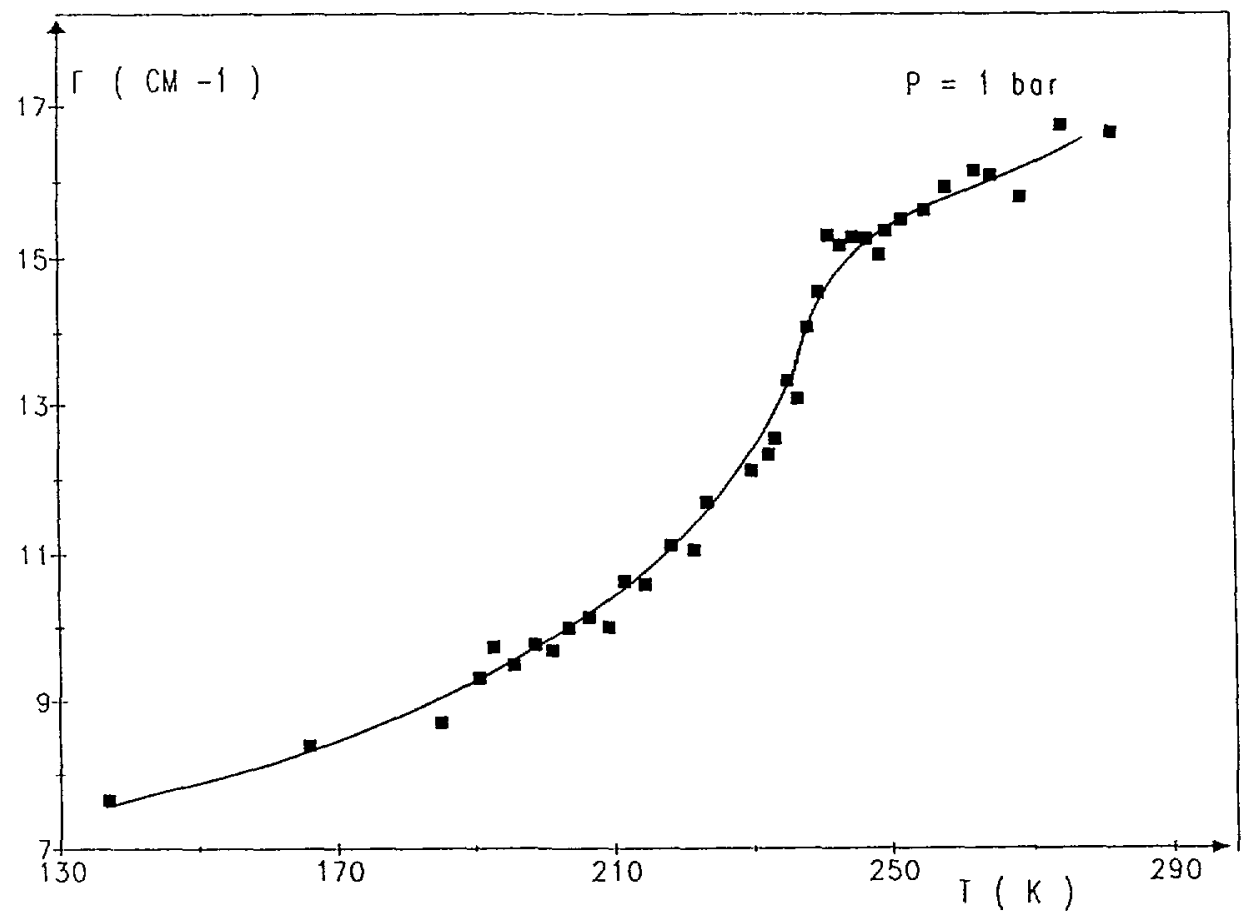

Fig. 4. - Linewidth dependence versus temperature at atmospheric pressure of the central band present in the $50-130 \mathrm{~cm}^{-1}$ spectral range of p-quaterphenyl crystal. The full curve is a guide to the eye. 

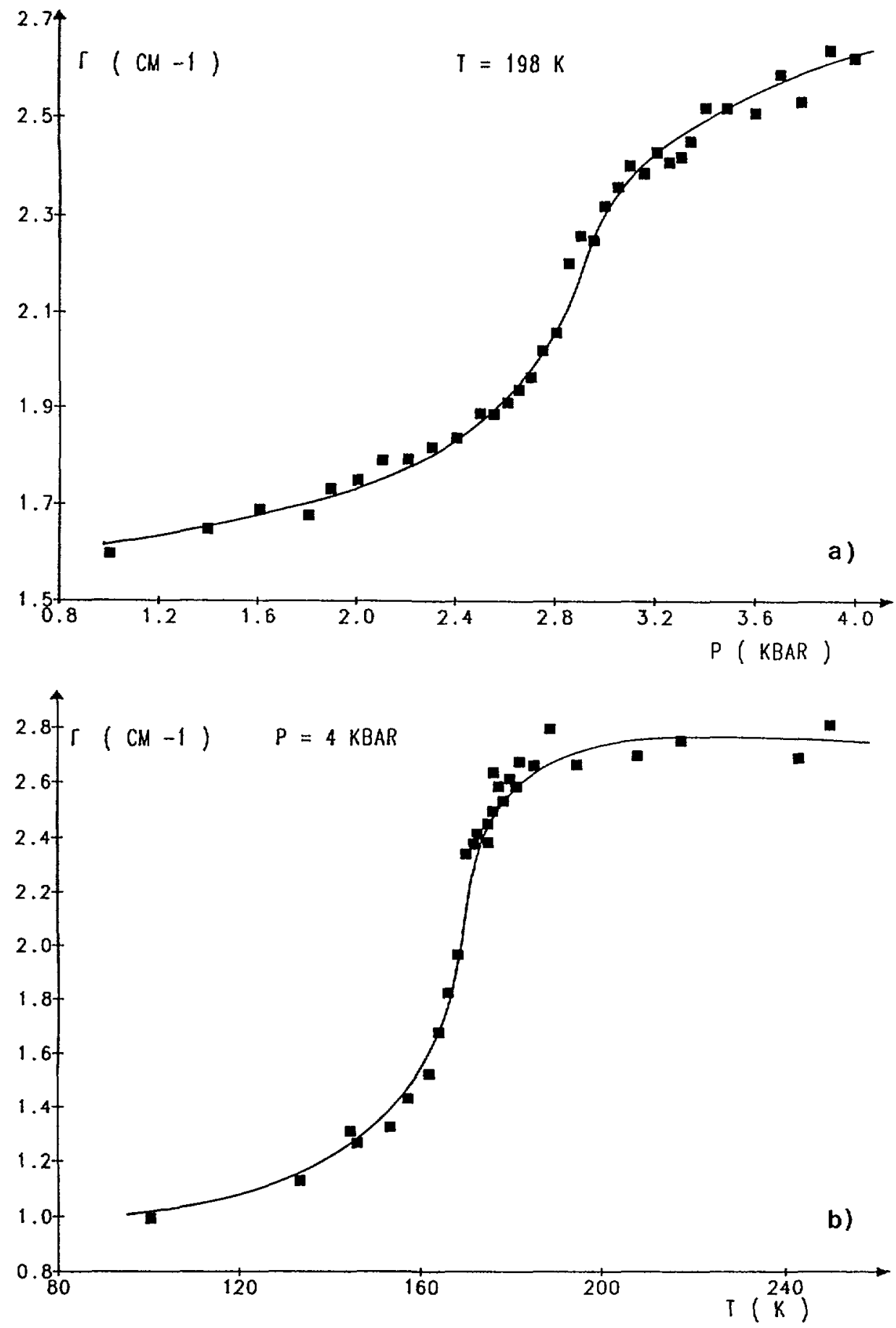

Fig. 5. - Examples of linewidth dependence versus pressure at constant temperature $T=198 \mathrm{~K}$ (a) and of linewidth dependence versus temperature at constant pressure $P=4 \mathrm{kbar}$ (b) for the central band present in the $30-40 \mathrm{~cm}^{-1}$ spectral range of p-quaterphenyl crystal. The full curves are guides to the eye. 


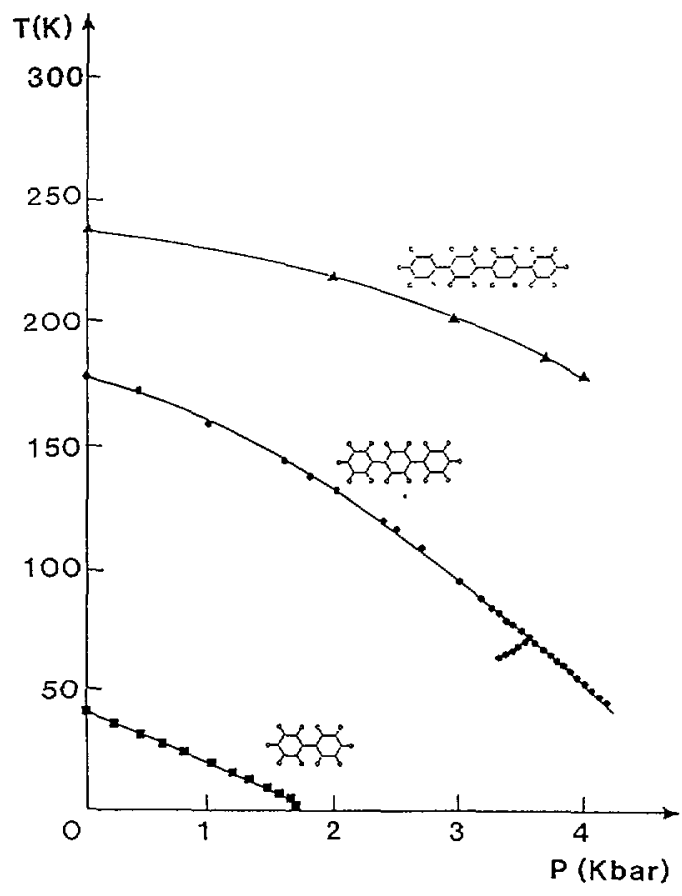

Fig. 6.

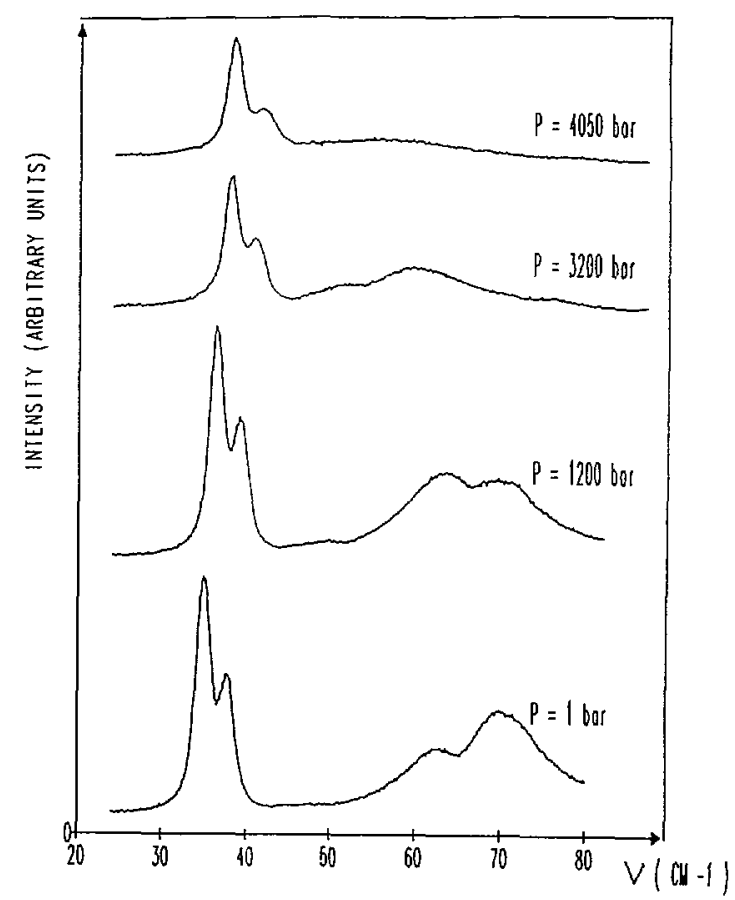

Fig. 7.

Fig. 6. - Phase diagrams of the biphenyl, p-terphenyl and p-quaterphenyl crystals.

Fig. 7. - Evolution of the $20-80 \mathrm{~cm}^{-1}$ spectral range of p-quaterphenyl at different pressures and at constant temperature $T=175 \mathrm{~K}$.

becomes strongly damped close to the transition and seems to disappear in the high temperature phase. In this phase only one very large band is then apparent and it becomes impossible to fit with more than one Lorentzian function. The evolution of the frequency is also remarkable : up to $1.6 \mathrm{kbar}$, it normally increases but, for higher pressures, a drastic change of behaviour occurs, i.e. the frequency strongly decreases.

\section{Discussion.}

At atmospheric pressure X ray [17], N.M.R. [20] and recent incoherent neutron scattering [26] studies have shown the order-disorder character of the transition mechanism. Based on symmetry considerations concerning the parity of the internal torsional mode relative to the inversion [14], one could expect similarities between the biphenyl and p-quaterphenyl structural instabilities. Actually the experimental results show a clear analogy between pterphenyl and p-quaterphenyl. In these two cases the local potential has a double-well shape, the height of its barrier passing from $1.05 \mathrm{kcal} / \mathrm{mole}$ in $\mathrm{p}$-terphenyl to $1.85 \mathrm{kcal} / \mathrm{mole}$ in $\mathrm{p}$ quaterphenyl at atmospheric pressure [20]. At room temperature, the frequency of the individual jump motion of these molecules in their double-well potential are respectively $\tau^{-1}=2.7 \mathrm{~cm}^{-1}$ and $\tau^{-1}=1.6 \mathrm{~cm}^{-1}$. Our Raman spectra, in the disordered phase, show a broadening of the lines which could come from this relaxational process following the relation [27-29]:

$$
\Gamma=(a+b T)+c\left(\tau / 1+\omega^{2} \tau^{2}\right)
$$



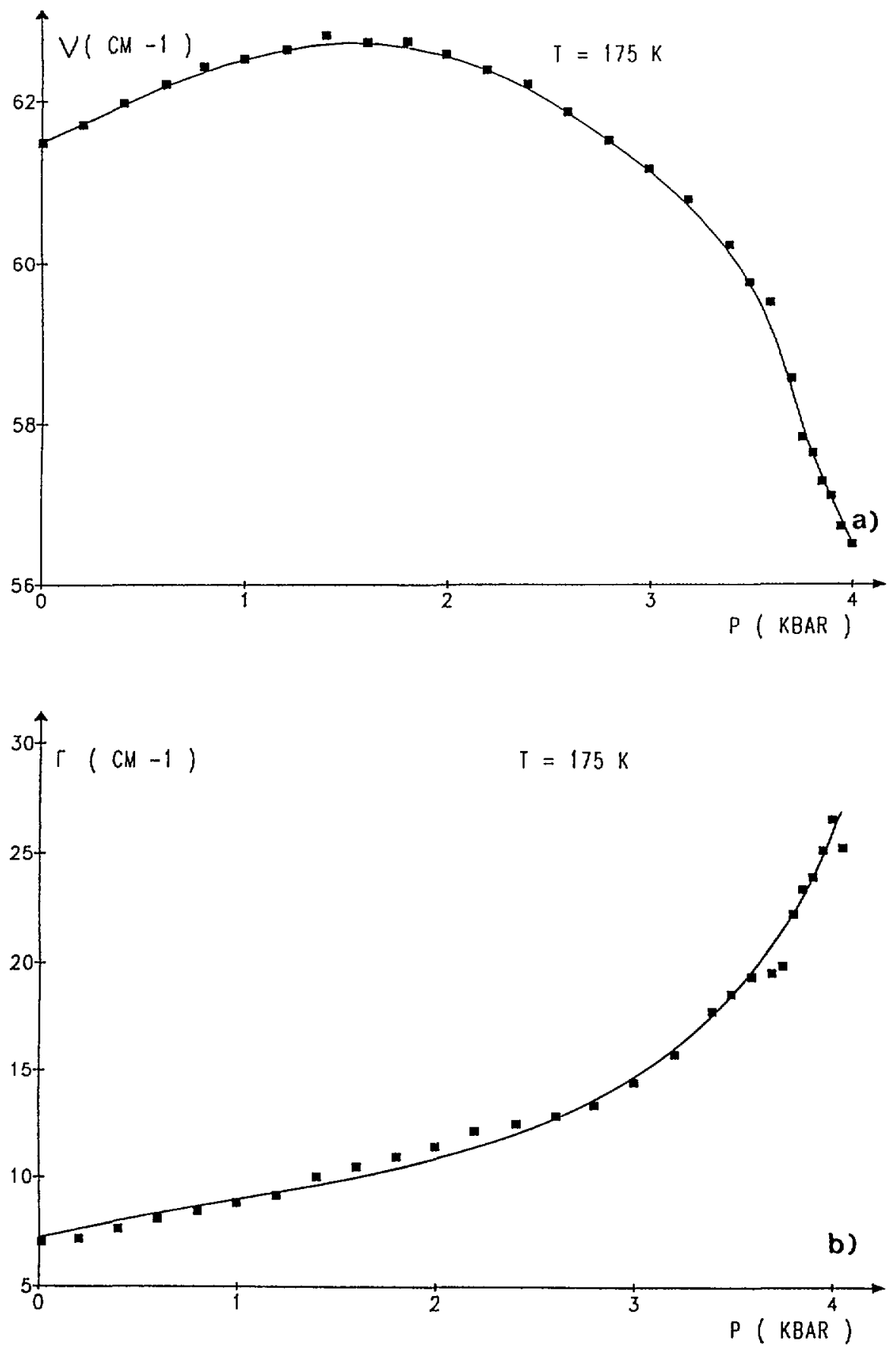

Fig. 8. - Frequency (a) and linewidth (b) dependence versus pressure at $T=175 \mathrm{~K}$ of the band of $\mathrm{p}$ quaterphenyl located at $61.5 \mathrm{~cm}^{-1}$ at atmospheric pressure. The full curves are guides to the eye. 
where $\omega$ is the frequency of the phonon. In this expression, the first part corresponds to the classic anharmonic broadening and the second one describes the relaxation effect. In pquaterphenyl, as previously shown in p-terphenyl [25], the term $\omega^{2} \tau^{2}$ is much larger than unity and the second part of the above equation is expected to be actually negligible. The residence time in a well being much larger than the phonon period, the disorder can be considered as static for these modes. The linewidth broadening, which appears in the ordered phase, is then attributed to the progressive setting of disorder when approaching the transition. Indeed disorder breaks the translational symmetry of the crystal and so some modes of the whole Brillouin zone can become active in Raman scattering, inducing a broadening of dispersive modes. This interpretation was already applied to describe the Raman results around the order-disorder phase transition of p-terphenyl. Let us notice that such a broadening is not expected around a displacive phase transition, which is seen as an order to order transition. This was indeed reported in biphenyl where the modes, other than the soft ones, did not present any anomaly on their width at the transition [11]. So, our Raman scattering study gives a further support for the order-disorder mechanism in pquaterphenyl at atmospheric pressure.

Under pressure such a broadening persists. The inflexion points in the $\Gamma(T)$ or $\Gamma(P)$ were used to determine the phase diagram of p-quaterphenyl. It is shown in the figure 6 together with the ones of biphenyl and p-terphenyl. First, the p-quaterphenyl phase diagram gives, at equal pressure, transition temperatures higher than biphenyl and p-terphenyl ones. This agree with the fact that the $A$ parameter for intramolecular potential is higher when the number of pairs of repulsive hydrogen atoms is larger. Moreover, the p-quaterphenyl transition temperature decreases with increasing pressure following a non-linear behaviour. This confirms our description of the competing forces in this series of molecules : the pressure increases the intermolecular forces (described by the $L$ parameter) so that the barrier height is reduced and the transition temperature shifts towards the low temperatures. We can then expect to observe a continuous change from an order-disorder character to a displacive one passing through an intermediate character. For such an intermediate case, the dynamical response is rather complex both in its theoretical $[2,30]$ and experimental $[1,31]$ aspect. From the Raman point of view, the signature is expected to present simultaneously the orderdisorder character (broadening of lines) and the displacive one (softening of a mode).

Figure 8a shows, for p-quaterphenyl, a mode whose frequency does not exhibit a normal behaviour versus pressure, i.e., above $1.6 \mathrm{kbar}$, its frequency decreases with pressure with a larger and larger slope when approaching the transition pressure and above $P_{\mathrm{c}}$ the mode seems to disappear. Such a behaviour can be associated to a soft mode located at zone boundary. In $\mathrm{p}$-quaterphenyl the high temperature instability, being located at the point $\mathrm{C}$ $(1 / 21 / 20)$ is twice degenerated [15] and two soft modes may be expected. The same is true in p-terphenyl where these two modes have indeed been observed [31]. No clear assignment of the second soft mode in p-quaterphenyl has been done. At 4 kbar, the dynamical character of the transition is not yet purely displacive : the broadening of the non-soft line is still clearly observed in the figure $5 \mathrm{~b}$. Let us notice that the linewidth of the soft mode also increases much on approaching $P_{\mathrm{c}}$, as shown in figure $8 \mathrm{~b}$. The interpretation of this phenomenon is maybe more complicated in this intermediate case [32].

Another interesting point is that p-quaterphenyl presents a continuous phase transition at atmospheric pressure. This is allowed as the irreductible representation of the space group at the point $\mathrm{C}$ fulfills the Landau and Lifschitz condition (no third order invariant in the free energy expansion). The same condition was fulfilled in p-terphenyl, the structural instability being located at the same point. However in this compound the phase transition is certainly already very weakly first order at atmospheric pressure [5]. Actually, the low value of the 
exponent $\beta$ for the order parameter $(\beta \cong 0.14$ ) could be either attributed to this weakly first order character [33] or, according to other authors, to a low dimensional character of the transition [34, 35]. Moreover this transition becomes strongly first order even under weak pressure $[1,5,12,13]$. So, under pressure, the analysis of the scattering function of $\mathrm{p}$ terphenyl in the intermediate case was experimentally difficult by all techniques due to the marked first order character. Such problems will not exist in p-quaterphenyl. The continuous character of the transition, preserved at all studied pressures, open new opportunities for the study of the mechanism of structural instabilities with character intermediate between orderdisorder and displacive.

\section{References}

[1] Girard A., Delugeard Y. and Cailleau H., J. Phys. France 48 (1987) 1751.

[2] Raich J. C. and Bernstein E. R., Mol. Phys. 53 (1984) 597.

[3] Cailleau H., Modern Problems in Condensed Matter Sciences, R. Bline and A. Levanyuk Eds. (V. W. Agranovich and A. A. Maradudin, North Holland, 1986) p. 71.

[4] Baudour J. L., Delugeard Y., Cailleau H., Acta Cryst. B 32 (1976) 150.

[5] Callleau H., Baudour J. L., Meinnel J., Dworkin A., Moussa F. and Zeyen C. M. E., Faraday Discuss. Chem. Soc. 69 (1980) 7.

[6] Toudic B., Cailleau H., Gallier J. and Lechner R. E., J. Phys. France accepted for publication.

[7] Cailleau H., Thesis University Rennes I (1981).

[8] Moussa F., launois P., Lemée-Cailleau M. H. and Cailleau H., Phys. Rev. B Rapid Commun. 36 (1987) 8951.

[9] Launois P., Moussa F., Lemée-Cailleau M. H. and Cailleau H., Phys. Rev. B 40 (1989) 5042.

[10] Lemée-Cailleau M. H., Girard A., Cailleau H., Delugeard $Y$. and Pruzan P., Ferroelectrics 105 (1990) 147.

[11] GiRARD A., Thesis University Rennes I (1983).

[12] LaUnoIS P., Thesis University Paris-Sud Orsay (1987).

[13] Toudic B., Launois P., Moussa F., Girard A. and Cailleau H., Ferroelectrics 80 (1988) 241.

[14] HeINe V. and Price S., J. Phys. C 18 (1985) 5259.

[15] ZaK J., CASHER A., GluCK H. and GUR Y., The Irreductible Representations of Space Groups (Benjamin, New York, 1969).

[16] Cailleau H., Messager J. C., Moussa F., Bugaut F., Zeyen C. M. E. and Vettier C., Ferroelectrics 67 (1986) 3.

[17] Delugeard Y., Desuché J. and Baudour J. L., Acta Cryst. B 32 (1976) 702.

[18] Baudour J. L., Delugeard Y. and Rivet P., Acta Cryst. B 34 (1978) 625.

[19] Ecolivet C., Toudic B. and SANQuer M., J. Phys. Colloq. France 42 (1981) C6-779.

[20] Toudic B., Gallier J., Rivet P. and Cailleau H., Solid State Commun. 47 (1983) 291.

[21] Bolton B. A. and Prasad P. N., Chem. Phys. 35 (1978) 331.

[22] Girard A., Delugeard Y., Lemee M. H., Pruzan P. and Syfosse G., Proceeding

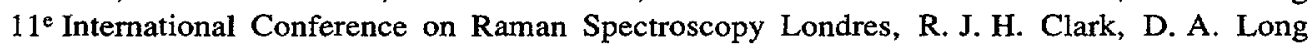
Eds. (John Wiley and Sons, Chichester, 1988) p. 491.

[23] Takeuchi H., Suzuki S., Dianoux A. J. and Allen G., Chem. Phys. 55 (1981) 153.

[24] Natkaniec I., Bielushin A. V. and Wasiutynski T., Phys. Stat. Sol. 105 (1981) 413.

[25] Girard A., Sanquer M. and Delugeard Y., Chem. Phys. 96 (1985) 427.

[26] Toudic B. and CODDENS G., Private Communication.

[27] Bougeard D. and NovaK A., Solid State Commun. 27 (1978) 453.

[28] Andrade P. R. and Porto S. P. S., Solid State Commun. 13 (1973) 1249.

[29] Sourisseau C. and LuCazeau G., J. Raman Spect. 8 (1979) 311. 
[30] AUbry S., Thesis University Paris VI (1975).

[31] Lemé-CAIlleau M. H., Thesis University Rennes I (1989).

[32] Bourges Ph., Ecolivet C., Mierzejewski A., Delugeard Y. and Girard A., «Phonons 89 », S. Hunklinger, W. Ludwig, G, Weiss Eds. (World Scientific Singapore, 1990) p. 1147.

[33] HÜlLER A. and PRESS W., The Plastically Crystalline State, J. N. Sherwood Ed. (John Wiley and Sons New York, 1979) p. 345.

[34] Guillon T., Conradi M. S. and Rigamonti A., Phys. Rev. B 31 (1985) 4388.

[35] Borsa F. and Rigamonti A., Structural Phase Transition, K. A. Müller, H. Thomas Eds. (Springer-Verlag Berlin, 1991) p. 83. 


\section{Revue de livres}

Theory of Simple Liquids (2nd ed.)

J. P. HANSEN and I. R. MCDONALD

(Academic Press, London, New York, 1990) 556 p., \$24.50.

Since the appearance of its first edition, Hansen and McDonald's book « Theory of Simple Liquids » has become one of the most popular sources of information for people whose scientific interest is connected with liquids. Now, we have at hand the second edition of this book. The new edition has been rearranged and considerably extended relative to the previous one. All chapters have been updated and modified with most of them extended. Three new chapters have been added, devoted to ionic, metallic and molecular liquids. The book consists of twelve chapters. The liquid state is characterized in the introductory, chapter 1. Chapter 2 presents basic ideas of statistical mechanics with particular emphasis on molecular distribution functions. For the last two decades, computer « experiments $\gg$ have played a very important role in the development of liquid-state physics. Chapter 3 gives a brief account of computer simulation methods, both Monte-Carlo and Molecular Dynamics. The application of diagrammatic methods in the modern theory of dense fluids is discussed in chapter 4. Pair distribution function is the very important characteristic of a liquid state. Chapter 5 presents theoretical methods used in calculation of the pair distribution function of a fluid for particular types of potential, as well as theories for other distribution functions. Perturbation theories often resorted to various aspects of the liquid state are treated in chapter 6 . The next three chapters are devoted to a discussion of the microscopic dynamics and transport properties of simple, dense fluids. Chapter 7 deals with the general formalism of time-dependent correlation functions and response functions. General properties of timedependent correlation functions are there described. The velocity autocorrelation function and selfdiffusion problems are considered as examples. Linear-response theory, properties of response functions and the application of the linear-response formalism are also presented. The link between microscopic time-dependent theories and hydrodynamics approach is considered in chapter 8 entitled « Hydrodynamics and Transport Coefficients ». Chapter 9 deals with the microscopic theories of timecorrelation functions where the concept of memory function plays a key role. There it is shown how the memory-function approach can be formalized through the use of projection-operator methods. The calculations of the memory function based on the ideas of "generalized hydrodynamics ", modecoupling approach and kinetic theories are also explored. Ionic liquids are discussed in chapter 10, whereas chapter 11 is concerned with the simple liquid metals. Although the title of this book would suggest that it is devoted only to atomic liquids, chapter 12 shows how the basic ideas developed in the preceding sections can be applied to molecular liquids. In this chapter the molecular pair distribution function and side-side distribution functions are discussed and the molecular expressions for the static dielectric constant of polar fluids are analyzed. Finally, a review of the interaction-side diagrams, interaction-side models, perturbation theories and reorientational time-correlation functions is given. Moreover the book contains an extensive and very useful list of references and five Appendices where some mathematical details of few problems appearing in the book are presented to the reader in more detail.

The book is published by Academic Press with utmost care. The quality of the paperback edition is also very high. The book is very interesting and should be very useful for everyone working in the field of the physics of liquids. The book is written in a very instructive way, however it requires from the reader a good background in elementary statistical mechanics. I think that this book should be strongly recommended to graduate and postgraduate students of physics and physical-chemistry who intend to do their research on liquids or dense fluids. Specialists should also have this book within their reach as a very useful reference guide. Those familiar with the first edition of the book of Hansen and McDonald will surely find the second edition valuable.

Tadeusz BANCEWICZ. 


\section{Order, Disorder and Chaos in Quantum Systems}

Edited by P. EXNER and H. NEIDHARDT

(Birkhauser Verlag ; Basel, Boston, Berlin, 1990) 360 p., FS 98, DM 112.

Interest in chaos in quantum systems has grown rapidly in recent years. The book edited by P. Exter and $\mathrm{H}$. Neidhardt assembles the contributions presented at the conference « Order, Disorder and Chaos in Quantum Systems » held at Dubna on October 17th-21st, 1989. The majority of the articles is devoted to the theory of Schrödinger operators : spectra, scattering and semiclassical behavior. This part of the proceedings could be rather included in the « orderly » category. A smaller, but the most interesting part of the book is devoted to the study of modifications introduced by quantum mechanics into the dynamics of classical systems which manifest deterministic chaotic behavior. This problem is referred to as «quantum chaos». The article by Seba deals with the properties of quantized classically chaotic systems which are illustrated on a solvable singular billiard model. Three other papers are related to the most popular model for the investigation of quantum dynamical chaos - the kicked rotator. The paper by F. M. Izrailev deals with the relevance of localization to quasi-energy statistics whereas the paper by B. Milek and P. Seba considers the problem of singular contributions to the quasi-energy spectrum in the kicked rotator with separable perturbation. The paper by G. P. Berman and F. M. Izrailev is devoted to the relation between correlation functions and spectrum statistics in the region of quantum chaos. The third part (entitled Other Topics) of the proceedings covers some stochastic models of growth, Sturm-Liouville problems and generalized functions and their applications.

To be honest, the various parts of the proceedings cannot be said to preserve the right kind of balance between order, disorder and quantum chaos. The articles nonetheless are on a high scientific level and are intended for scientists working on dynamical systems and mathematical physics.

\section{Przemysław SzLACHETKA.}

\section{Nuclear Structure from a Simple Perspective}

\section{Richard F. CASTEN}

(Oxford University Press, 1990) 400 p., $£ 45.00$.

Though nuclear physics research is under threat in Britain and several other countries in Europe, there is still a need to train young research workers in the field. Casten has provided here an intuitive introduction for graduate students which very much reflects his own personal interests and understandings. Though not designed to replace one of the standard texts, the author argues that these are often very daunting to the uninitiated. Thus the present volume avoids such mathematical technology as heavy angular momentum algebra and very few of his formulae in fact extend into a second line! The only real prerequisite for working from the book is having followed a standard course on quantum mechanics.

The work is mainly a description of the PHYSICS of the shell and collective models of classical low energy nuclear physics. Thus there are no pions or quarks in Casten's nuclei. It is furthermore concerned mainly with heavy nuclei (the lightest nucleus explicitly mentioned in the index seems to be chlorine) so that little emphasis is put on the physical nucleon-nucleon scattering.

On the other hand, what Casten does he does well. I liked his presentation of rotations and vibrations of deformed nuclei and the subsequent development of the interaction boson approximation and grouptheoretic techniques. This then allowed him to give an introduction to the currently important topic of the study of high spin states in heavy ion reactions. Following the pioneering work on these at Daresbury, this field is likely to blossom further with the displacement of the EUROGAM detector to France next year.

As a particle physicist, who strayed late in life into nuclear reactions at high energies, I found this a very readable book which did not make me feel guilty by including large chunks of formalism which I am tempted to skip! I suspect that new graduate students will be equally happy with their omission. 


\section{Physics of materials}

\section{R. J. WEISS}

(Hemisphere Publishing Corporation, Taylor and Francis, 1990) 447 p., $£ 42.00$.

Le livre «Physics of Materials » représente une refonte d'un ouvrage intitulé « Solid State Physics for Metallurgists » paru il y a 25 ans. L'objectif de l'ouvrage (qui lui donne d'ailleurs un aspect quelque peu fourre-tout) est de regrouper l'ensemble des connaissances et des techniques expérimentales de base nécessaires à la compréhension des matériaux et de leurs applications. Par rapport à la version précédente, l'auteur indique qu'il a souhaité faire apparaître dans son livre les progrès récents sur les composites, l'interaction lumière matière (lasers, fibres optiques) et la supraconductivité.

Aussi, dans cette logique, l'ouvrage débute par l'atome d'hydrogène et l'équation de Schrödinger pour finir par la description des fibres optiques et de leurs applications.

Les principaux thèmes abordés en cours de route sont :

- Fondements de la mécanique quantique : atomes, molécules, théorie électronique des solides dans un réseau périodique d'atomes, modèles de bandes, structure électronique des métaux de transition et des terres rares, réseaux de spins en interaction et magnétisme des métaux de transition.

- Oscillateurs harmoniques. Modèles de chaleur spécifique de réseau, électronique et magnétique.

- Radioactivité des noyaux atomiques, interactions particules élémentaires-noyaux.

- Techniques expérimentales : différentes méthodes expérimentales d'analyse des métaux purs et des alliages. Analyse des matériaux par techniques de diffraction et diffusion de rayons $\mathrm{X}$ et de neutrons. Spectroscopie des solides par techniques $\mathrm{X}$ et optiques.

- Analyse expérimentale des propriétés de transport des solides : résistivité, magnétorésistance, résonance cyclotron, effet Hall, supraconductivité.

- Propriétés thermodynamiques des solides : mesures de chaleurs spécifiques et de conductivité thermique. Informations obtenues par ces techniques. Mesures de transitions de chaleurs de transition de phase sur les matériaux et les alliages.

- Mesures de magnétisation, de résonance paramagnétique électronique. Analyse des matériaux par résonance magnétique nucléaire.

Le livre se poursuit par un chapitre décrivant dans le cas du cuivre et du fer quelles sont les informations tirées de chaque type de mesure et dans quelle mesure on peut tirer de ce "puzzle " des éléments guidant les études théoriques et les calculs. Les conclusions sont plutôt encourageantes en ce qui concerne une compréhension semiquantitative des phénomènes; elles sont assez pessimistes en ce qui concerne la connaissance des densités d'état et, encore plus en ce qui concerne le passage à des alliages d'intérêt pratique.

Enfin, un chapitre de conclusion très prospectif (« the photon revolution ») présente en particulier l'« explosion » de la technologie et des applications des fibres optiques ainsi qu'une comparaison entre le transport et le stockage d'informations par des techniques optiques et électriques.

L'auteur donne également à la fin du livre une liste de références et quelques valeurs numériques. La bibliographie aurait gagné à être plus détaillée compte tenu du rôle très introductif des exposés. Chaque chapitre est suivi d'un résumé utile et clair et de quelques «problèmes » qui sont en fait des questions astucieuses et souvent liées à des applications pratiques, correspondant à un aspect concret des problèmes.

De part son principe même, il est clair que ce livre ne peut guère aller au fond des problèmes puisqu'il aborde une quinzaine de sujets dont chacun nécessiterait un livre de volume égal à celui-ci.

A notre avis certains chapitres n'apportent que peu de chose car ils traitent de sujets largement abordés par les manuels universitaires : physique quantique élémentaire, fonctions d'ondes électroniques dans les solides et les molécules, modèles de chaleur spécifique. De plus l'exposé n'est ni particulièrement pédagogique, ni particulièrement original.

L'aspect le plus intéressant du livre est au contraire, à notre avis, la description des techniques expérimentales et les exemples d'applications et des courbes expérimentales que donne l'auteur: les indications données sont en général suffisantes bien que brèves et le regroupement des différents exposés facilite la comparaison des informations données par chaque méthode. L'auteur donne même 
dans certains cas des schémas assez détaillés de montages expérimentaux. Les descriptions comparées de 1 'analyse des solides par différentes techniques de rayons $X$ et neutrons sont particulièrement riches en informations sur les apports et les applications de ces techniques. C'est à notre avis la partie la plus intéressante du livre mais la description des techniques de mesure de propriétés de transport et de caractéristiques thermiques ainsi que celle des mesures nucléaires la complètent bien.

Bien que l'auteur fasse part de son intérêt pour les matériaux composites dans la préface, les nouveaux problèmes posés par l'étude des matériaux hétérogènes et granulaires ne sont presque pas abordés : on aurait, en particulier, aimer trouver une description d'analyse des géométries fractales de roches ou d'agrégats par des techniques neutrons.

En conclusion, de part la diversité des sujets abordés, le livre «Physics of Materials » intéressera les étudiants, chercheurs et ingénieurs qui ont besoin d'acquérir rapidement une vue d'ensemble simple des techniques expérimentales de l'étude des matériaux.

\section{J. P. Hulin.}

\section{Solid State Physics (2nd edition)}

J. R. HOOK and H. E. HALL

(John Wiley \& Sons Ltd, 1991) 474 p., with index, problems and notes for answers, $£$ 17.95.

This is the book your reviewer needed three years ago, before starting to give an introductory course on solid state physics to second year London University undergraduates. None of the other books available has taught him so much, and many of them are totally incomprehensible to the absolute beginner. This edition has a new second author who has considerably revised the contents, bringing in contemporary topics such as « warm » superconductors, the scanning tunneling microscope, the quantum Hall effect and neutron-phonon scattering.

The main virtue of the text for students at all levels, from beginners to postgraduates, is the steady progression from simple concepts, elegantly presented, to the full complexity of the subject. Other books teach jargon for its own sake. This one introduces new vocabulary as needed, often after the concepts have already been developed in a simple model. Following the clear and well illustrated first chapter on crystal structure - up to a qualitative discussion of bonding mechanism - the second chapter begins with a fully worked out presentation of the vibrations of a one-dimensional chain of atoms. The subtleties of the optical and acoustic branches of the dispersion relation are presented in a way which fortifies the reader's intuition before moving into three dimensions.

The concept of phonons is introduced in chapter 2, and is used throughout the book. Chapters 3 and 4 , on the nearly free electron model and the tight binding approximation, relate the two approaches to one another - rather than treating them as disconnected rival theories - and explain the concepts of crystal momentum and effective electron mass. This prepares the ground for chapters 5 and 6 on Semiconductors and Semiconductor devices, a natural endpoint - for a short course - which can be reached without having to tackle all of the «big ideas » of condensed matter theory.

The next chapters range widely : diamagnetism and paramagnetism ; the varieties of magnetic order, including spin density waves, and Ferromagnetic domains ; properties of insulators ; superconductivity, with clear qualitative explanations of the generation of Cooper pairs, the reasons for infinite conductivity and the special properties of one of the ytrium-barium-copper layered oxides.

As a blessed relief to the weaker student, the reciprocal lattice is not introduced until page 319 , in chapter 11, a general discussion of waves in crystals. This paves the way for the three last chapters : the scattering of neutrons and electrons from solids ; real metals ; and low dimensional systems.

Yet again the Manchester Physics series has produced a book with exactly the right combination of challenge and helpfulness to carry students into an important branch of the subject.

David J. MILLER. 


\section{Optics}

W. T. WELFORD F.R.S.

(Oxford University Press, 1988) 155 p., $£ 17.50$.

An unusual booklet, now at the third edition where optics is described with historical connections from Euclid to Galileo, even recalling Newton - always well detailed, with clear figures and formulas, and an essential bibliography.

Full of a cultured humor, every chapter is introduced by a quotation from James Joyce's Ulysses, baring those devoted to fiber optics, detectors and light polarization.

The distinctive feature is an exceptional richness of concepts and data, both physical and technical ; wealth is probably to the detriment of lucidity in chapter I, where basic ideas in optics are introduced without wasting words : the reader is initiated in ondulatory theory of light, moving from geometrical optics to Schrödinger equation, through luminous sources, quantum and thermal detectors, photometric units, spatial and temporal coherence.

Evident drawback of this chapter are continual quotations of other texts : for instance the reader is referred to « Radiation and quantum optics " (OPS3) by D.J.E. Ingram six times in few pages. The logic thread is lost in vain rather than profitably deepened.

More linear is the path in the chapter devoted to geometrical optics, where the calculation of the powers of the components of an achromatic doublet is rather effective from a didactical point of view.

The other chapters are unexceptionable for completness, but some technical data should be added to the chapter on «Polarization», where polarizing microscopes are introduced without examining interference between beams polarized at right angles and electro- and magneto-optical effects are not mentioned, even if basic for liquid crystal displays.

In chapter III, the author deals with the diffraction pattern from a square aperture in the far field and that of a very long slit in the near-field region. These results are reminded in chapter $V$ with regard the calculation of the point spread function of an optical instrument by Fourier transform formalism, up to the spatial frequencies of an object and its image, and to the optical transfer function of an optical system.

A large part of chapter entitled «Interferometers and spectroscopes» is properly devoted to dispersion, resolution, and light-gathering power of a prism and a grating, without neglecting the Michelson interferometer and the Fourier-transform spectroscopy, the Fabry-Perot scanning interferometer and the principle of multilayer high reflecting coatings.

Unfortunately the section on «Detection and measurements of light 》 is very short : the photoelectric effect is described, as well as the principles of photomultiplier devices, whereas solid state detectors are only mentioned in spite of their importance in optics.

In the chapter on "laser light " the speckle pattern by a random diffuser is mentioned ; holography and holographic interferometry are deeply discussed. Also the Abbe theory on the image formed in the Fourier plane is introduced in order to explain the spatial filtering process.

Chapter VIII is devoted to fiber optics as carrier of energy and information by total internal reflection, for both step index and graded index guides. The use of these devices in telecommunications and for digital transmission is investigated with particular attention to signal attenuation and signal-tonoise ratio.

Basically, it is a book of rare intelligence, without gratuitous or obsolete parts, without misprints or bold statements, certainly useful to specialists and those students willing to probe concepts, to understand the physical aspects and the profound meaning behind simple ancient instruments.

Elio MiraLdi. 


\section{Papers published in the September issue of JOURNAL DE PHYSIQUE II (JPII)}

\section{Short Communications}

Field-induced spirals from a confined cholesteric.

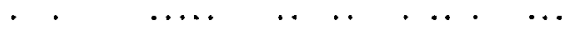

M. MTTOV and P. SIXOU

Festoon instabilities of slightly volatile liquids during spreading.

. $\quad$. $\quad . \quad$. $\quad . \quad$ C. REDON, F. BROCHARD-WYART and F RONDELEZ

Mesoscopic structure of polymer mediated microemulsion networks.

D. VOLLMER, U. HOFMEIER and H.-F. EICKE

\section{Chemical Physics}

Molecular layers of a polymer at the free water surface : microscopy at the Brewster angle.

. . . . . . . . E.K. MANN, S. HENON, D. LANGEVIN and J. MEUNIER

Theoretical results on toroidal vesicles.

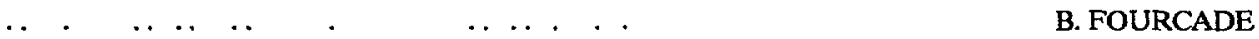

Ginzburg-Landau theory of aqueous surfactant solutions.

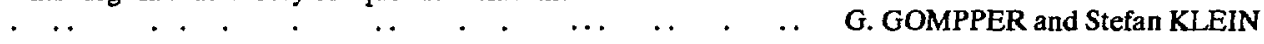

Swelling and rheological properties of poly methyl methacrylate thermoreversible gels.

. . . $\quad \ldots \ldots . .$. Zarmina FAZEL, Nazir FAZEL and Jean-Michel GUENET

Thermodynamics and hydrodynamics of chemical gels. II. Gels in binary solvents.

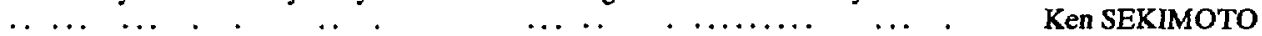

A study of the structure of highly concentrated phases of DNA by X-ray diffraction.

D. DURAND, J. DOUCET and F. LIVOLANT

\section{Book Reviews}

Short Communications. saisie, composition MATHOR3 $T_{E} X$

Other Communications : saisie MATHOR, composition PHOTOMAT

Impression JOUVE, 18, rue Saint-DenIs, 75001 PARIS

$N^{\circ}$ 203423F Dépôt légal : Septembre 1992 